\title{
THE EFFECT OF SPINAL ANESTHESIA ON THE RENAL ISCHEMIA IN CONGESTIVE HEART FAILURE ${ }^{1}$
}

\author{
BY REUBEN MOKOTOFF 2 AND GEORGE ROSS \\ (From the Medical Division, Montefiore Hospital, New York City)
}

(Received for publication December 22, 1947)

One of the effects of a decreased cardiac output in chronic congestive heart failure is a disproportionate decrease in the renal blood flow. We have calculated the renal fraction of the cardiac output to be reduced to about two-fifths of normal and have shown that there is marked efferent arteriolar constriction with increased intraglomerular filtration pressure in congestive heart failure (1). Although Merrill and co-workers (2) have demonstrated that renin is present in increased amounts in the renal venous blood of some patients with congestive failure, we wondered if renal vasoconstriction might also result from neurogenic stimulation when the cardiac output falls; in which case, hyperemia should be produced by blocking the reflex pathways. In the present study the interruption of the autonomic vasoconstrictor pathways was effected by means of high spinal anesthesia. As will be seen from the results obtained in these experiments, renal hyperemia does not occur in response to the abolition of sympathetic vasoconstrictor impulses.

\section{METHODS}

Fourteen patients with varying degrees of congestive heart failure were the subjects. They were examined in the post-absorptive state employing the clearance of mannitol (or sodium thiosulfate in two instances) as a measure of glomerular filtration rate, and the clearance of p-aminohippuric acid ${ }^{3}$ as a measure of effective renal plasma flow as described in a previous report (1).

After three or more control clearance periods were obtained, $48 \mathrm{mg}$. of ephedrine sulfate were injected intramuscularly in order to counteract any fall in arterial pressure, consequent to the high spinal anesthesia. The patient was then placed in the lateral position and the subarachnoid space entered between the levels of $\mathrm{L} 3$

\footnotetext{
1 This study was aided by a grant from the United States Public Health Service and the Martha M. Hall Foundation.

2 Martha M. Hall Foundation Fellow in Medicine.

${ }^{3}$ Liberal quantities of mannitol and p-aminohippuric acid were supplied by the Medical Research Division of Sharp and Dohme, Inc. Sodium thiosulfate was supplied by Winthrop and Co.
}

and L 4. Metycaine d,1-3-Benzoxy-1-(2-methylpiperidino) propane Hydrochloride (120-150 mg.) mixed with equal parts of spinal fluid was the anesthetic agent. Procaine was not used because it has an amino group in the para position of the benzene nucleus and would result in falsely high values for p-aminohippurate (3). Moreover, a longer acting anesthetic agent was desirable. After the metycaine was injected rapidly, the patient was placed in the prone position with the pelvis tilted at an angle of -10 to -15 degrees. This position was maintained for about 10 to 20 minutes after which the patient was turned flat on his back. In two instances, because of the patient's severe dyspnea and orthopnea, the lumbar puncture was made in the upright position. In two other cases, because of unsatisfactory ascent of the anesthesia, a second injection of metycaine was necessary before the test periods were started. The test clearance periods were started after the highest level of sensory anesthesia was reached which was usually between 25 and 40 minutes after spinal injection. In several instances when the anesthesia reached the first thoracic segment and there was almost complete intercostal paralysis, oxygen was administered. Artificial respiration was available, but was never required. Blood pressure was taken by auscultation of the brachial artery at frequent intervals during the control and anesthesia periods. The figures given in Table $I$ are the means of several readings in each period.

\section{RESULTS}

The maximal level of anesthesia was unsatisfactory in three patients, who consequently have been omitted from consideration. The data of the remaining eleven are summarized in Table I. It will be seen that the lowest level of anesthesia reached was the sixth thoracic segment. Smith and associates (4) have shown that with this degree of sensory anesthesia there is abolition of the reflex vasoconstrictor responses to anoxia, hypercapnia and tilting. We believe, therefore, had there been any reflex vasoconstrictor impulses reaching - the kidney they would have been effectively blocked.

As to the blood pressure changes in these patients, the only generalization that can be made is that the variations tended to be minimal. We were able to utilize the action of ephedrine in maintain- 
TABLE I

Effects of spinal anesthesia on renal circulation in congestive heart failure *

\begin{tabular}{|c|c|c|c|c|c|c|c|c|c|c|c|c|c|c|c|c|}
\hline \multirow[b]{2}{*}{ 葶 } & \multirow[b]{2}{*}{ 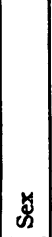 } & \multirow[b]{2}{*}{ 品 } & \multirow[b]{2}{*}{ 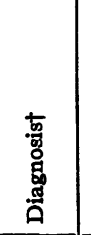 } & \multirow{2}{*}{ 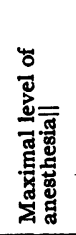 } & \multicolumn{3}{|c|}{$\begin{array}{l}\text { Glomerular } \\
\text { Filtration rate } \\
\text { cc. per min. }\end{array}$} & \multicolumn{3}{|c|}{$\begin{array}{l}\text { Renal plasma flow } \\
\text { cc. per min. }\end{array}$} & \multicolumn{3}{|c|}{$\begin{array}{l}\text { Filtration fraction } \\
\text { per cent }\end{array}$} & \multicolumn{2}{|c|}{$\begin{array}{l}\text { Blood pressure } \\
m m . H g\end{array}$} & \multirow[b]{2}{*}{ Remarks } \\
\hline & & & & & 흄 & 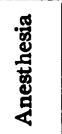 & 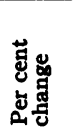 & 형 & $\begin{array}{l}\text { 芯 } \\
\text { 芯 } \\
\text { 总 }\end{array}$ & 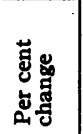 & 홈 & 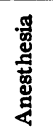 & 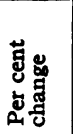 & 현 & 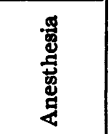 & \\
\hline $\begin{array}{l}\text { 1. C. R. } \\
\text { 2. I. F. }\end{array}$ & $\begin{array}{l}F \\
F\end{array}$ & $\begin{array}{l}36 \\
43\end{array}$ & $\begin{array}{l}\text { RHD } \\
\text { HHD } \\
\text { and } \\
\text { RHD }\end{array}$ & $\begin{array}{ll}\text { T } & 6 \\
\text { T } & 2\end{array}$ & $\begin{array}{l}48 \\
60\end{array}$ & $\begin{array}{l}38 \\
62\end{array}$ & $\begin{array}{r}-21 \\
+3\end{array}$ & $\begin{array}{r}88 \\
210\end{array}$ & $\begin{array}{r}75 \\
198\end{array}$ & $\begin{array}{r}-15 \\
-6\end{array}$ & $\begin{array}{l}55 \\
29\end{array}$ & $\begin{array}{l}51 \\
31\end{array}$ & $\begin{array}{l}-7 \\
+7\end{array}$ & $\begin{array}{l}110 / 84 \\
164 / 110\end{array}$ & $\begin{array}{l}78 / 60 \\
190 / 104\end{array}$ & Ephedrine omitted \\
\hline 3. A. M. & F & 16 & Cong. & T 2 & 778 & 69 & -10 & 127 & 118 & -7 & 61 & 58 & -5 & $166 / 90$ & $170 / 106$ & \\
\hline $\begin{array}{l}\text { 4. C. S. } \\
\text { 5. B. M. }\end{array}$ & $\frac{\mathbf{M}}{\mathrm{F}}$ & $\begin{array}{l}60 \\
50\end{array}$ & $\begin{array}{l}\text { ASHD } \\
\text { RHD }\end{array}$ & $\begin{array}{ll}T & 1 \\
T & 4\end{array}$ & $\begin{array}{l}85 \\
918\end{array}$ & $\begin{array}{l}72 \\
79\end{array}$ & $\begin{array}{l}-15 \\
-13\end{array}$ & $\begin{array}{l}234 \\
280\end{array}$ & $\begin{array}{l}206 \\
290\end{array}$ & $\begin{array}{r}-12 \\
+4\end{array}$ & $\begin{array}{l}36 \\
33\end{array}$ & $\begin{array}{l}35 \\
27\end{array}$ & $\begin{array}{r}-3 \\
-18\end{array}$ & $\begin{array}{l}108 / 60 \\
110 / 74\end{array}$ & $\begin{array}{l}98 / 60-70 \\
106 / 70\end{array}$ & No edema. Com \\
\hline $\begin{array}{l}\text { 6. E. Mc. } \\
\text { 7. J.S. } \\
\text { 8. S. B. }\end{array}$ & $\begin{array}{l}\mathbf{M} \\
\mathbf{F} \\
\mathbf{M}\end{array}$ & $\begin{array}{l}20 \\
35 \\
39\end{array}$ & $\begin{array}{l}\text { RHD } \\
\text { RHD } \\
\text { RHD }\end{array}$ & $\begin{array}{ll}\mathrm{T} & 1 \\
\mathrm{~T} & 6 \\
\mathrm{~T} & 1\end{array}$ & $\begin{array}{l}56 \\
73 \\
33\end{array}$ & $\begin{array}{l}76 \\
72 \\
31\end{array}$ & $\begin{array}{r}+36 \\
-1 \\
+6\end{array}$ & $\begin{array}{l}137 \\
243 \\
116\end{array}$ & $\begin{array}{l}170 \\
236 \\
171\end{array}$ & $\begin{array}{l}+24 \\
-3 \\
+47 \ddagger\end{array}$ & $\begin{array}{l}41 \\
30 \\
28\end{array}$ & $\begin{array}{l}45 \\
31 \\
18\end{array}$ & $\begin{array}{r}+10 \\
+3 \\
-36\end{array}$ & $\begin{array}{l}150 / 45 \\
110 / 80 \\
130 / 90\end{array}$ & $\begin{array}{l}130 / 40 \\
106 / 74 \\
110 / 70\end{array}$ & $\begin{array}{l}\text { pensation restored } \\
\text { Pyrogen reaction. }\end{array}$ \\
\hline 9. E. S. & $\mathbf{M}$ & 38 & HHD & T 3 & 99 & 118 & +19 & 307 & 373 & +21 & 32 & 32 & 0 & $185 / 125$ & $208 / 128$ & $\begin{array}{l}\text { Temp. rise to } 103^{\circ} \\
\text { Minimal edema. } \\
\text { Compensation re- }\end{array}$ \\
\hline $\begin{array}{l}\text { 10. F. I. } \\
\text { 11. J. L. }\end{array}$ & $\begin{array}{l}\mathbf{M} \\
\mathbf{M}\end{array}$ & $\begin{array}{l}43 \\
39\end{array}$ & $\begin{array}{l}\text { ASHD } \\
\text { ASHD } \\
\text { Mean c }\end{array}$ & $\begin{array}{cc}T & 5 \\
T & 3 \\
\text { change }\end{array}$ & $\begin{array}{l}61 \\
84\end{array}$ & $\begin{array}{l}55 \\
93\end{array}$ & $\begin{array}{r}-10 \\
+11 \\
0\end{array}$ & $\begin{array}{l}145 \\
213\end{array}$ & $\begin{array}{l}143 \\
229\end{array}$ & $\begin{array}{l}-1 \\
+8 \\
+1\end{array}$ & $\begin{array}{l}42 \\
39\end{array}$ & $\begin{array}{l}39 \\
41\end{array}$ & $\begin{array}{l}-7 \\
+5 \\
-2\end{array}$ & $\begin{array}{l}96 / 80 \\
98 / 80\end{array}$ & $\begin{array}{l}90 / 74 \\
96 / 70\end{array}$ & \\
\hline
\end{tabular}

* All values are averages of three or more periods.

† Cong. HD, RHD, ASHD, HHD = Congenital, rheumatic, arteriosclerotic and hypertensive heart disease, respectively.

$\ddagger$ This figure was omitted in calculating mean change, due to interfering pyrogen reaction.

\$odium thiosulfate clearance used as a measure of glomerular filtration rate.

II Determined as the highest level of absolute loss of sensation to pin prick.

ing the systolic pressure during high spinal anesthesia. In the one case (C. R.) in which it was omitted there was a moderate drop in the mean pressure. Ephedrine sulfate in the amounts used in these patients has been shown to have no effect on the renal circulation (5). We have confirmed this in control observations on two patients with severe congestive failure. Therefore, with only a single exception (C. R.), any changes in the renal circulation which were obtained, were not due to a decrease in driving force. Similarly, the use of ephedrine precluded the possibility that any renal hyperemia which might occur would be offset by the fall in mean pressure during anesthesia.

Except for the subjects E. Mc. and S. B., there was no significant change in either glomerular filtration rate or renal plasma flow in any of the patients. E. Mc. (Figure 1) had an increase in plasma flow of 24 per cent and an increase in glomerular filtration rate of 36 per cent in spite of a slight fall in systolic pressure. We have no adequate explanation for the unusual changes observed. C. R. had a decrease in all the functions studied which we attribute largely to the drop in mean pressure. Figure 2 (I. F.) illustrates the typical response seen in the majority of these patients. Taking the series as a whole, the mean change in the renal circulation is nil.

Patient S. B. developed a pyrogen reaction immediately after the spinal anesthesia. It will be seen that the renal plasma flow was increased by 47 per cent, the glomerular filtration rate was unchanged and the filtration fraction decreased to normal values. This is interpreted as being due to efferent arteriolar dilatation (6), and indicates that neurogenic control of the renal vessels is not required for its completion. The pyrogen reaction with its renal circulatory changes also occurs in the sympathectomized hypertensive patient (7).

It is of some interest to note that several of the patients who were dyspneic and orthopneic before spinal anesthesia could lie flat with no apparent discomfort while the clearance studies under anesthesia were completed. Apparently, the marked diminution of afferent impulses from atonic limbs and abdominal muscles, the decreased venous pressure secondary to venous stagnation with resulting decrease in reflex respiratory stimulation (8), produced the desired effects. 


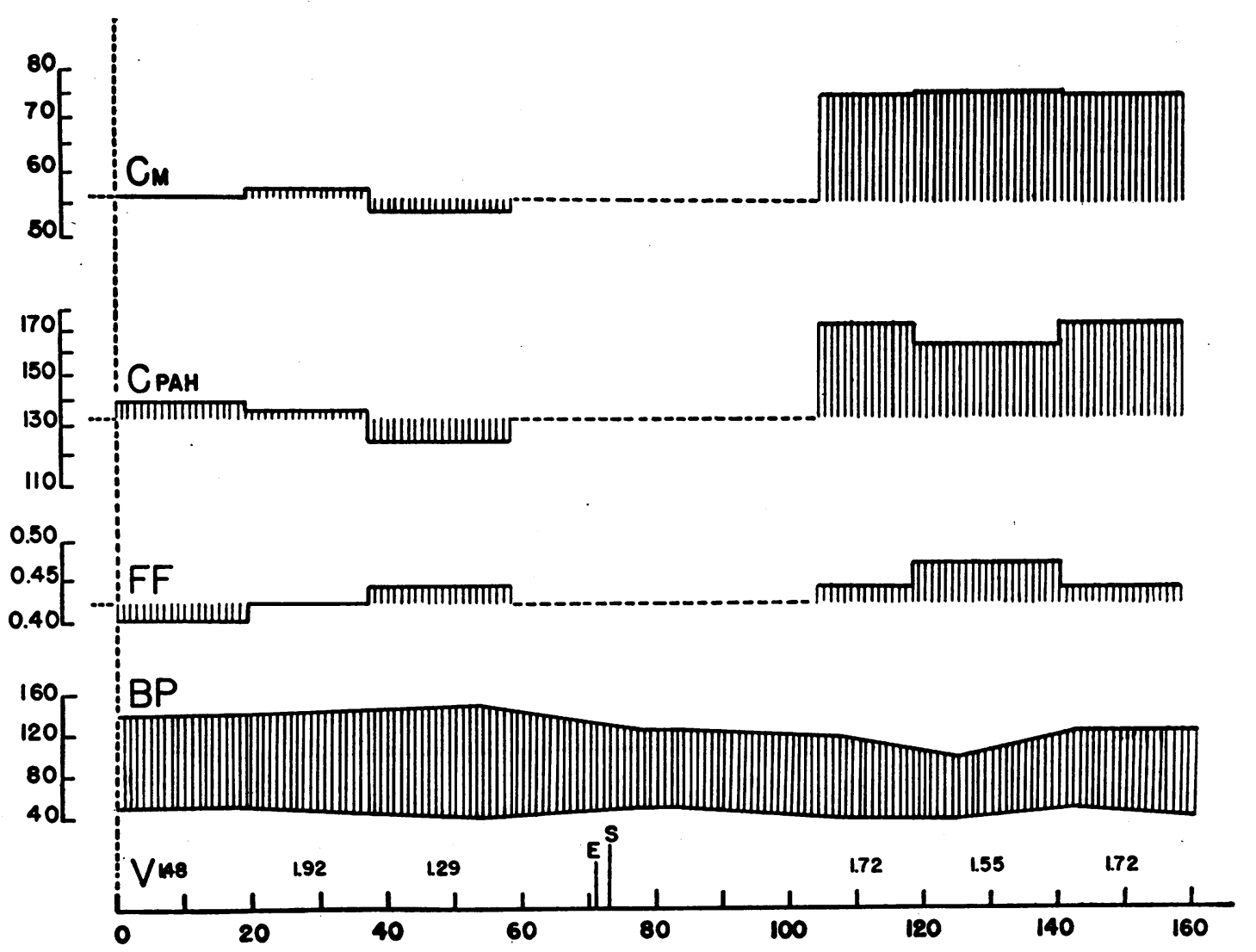

Fig. 1. The Unusual Response of the Renal Circulation to Spinal Anesthesia in Patient E. Mc. with Severe Congestive Failure

This patient had an increase in renal plasma flow and glomerular filtration rate of 24 and 36 per cent, respectively, during sensory anesthesia up to the first thoracic segment as compared to control periods before anesthesia. This occurred in spite of a drop in systolic pressure.

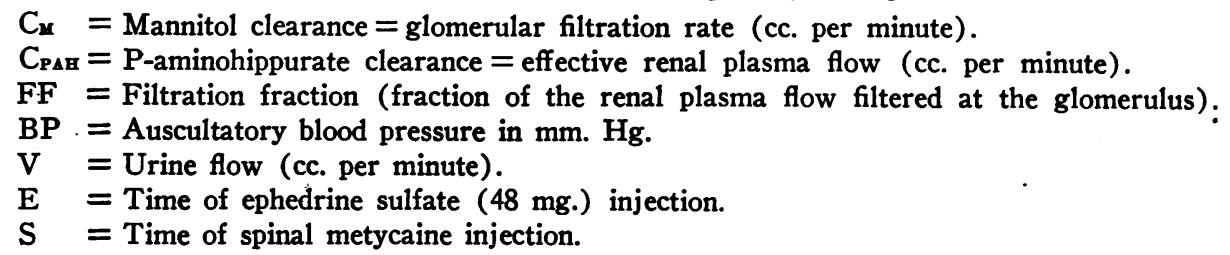

\section{COMMENTS}

Our results indicate that the renal ischemia with marked efferent arteriolar constriction and the concomitant reduction in the renal fraction of the cardiac output so regularly observed in established congestive failure, are not maintained by sympathetic activity. That reflex vasoconstriction with shunting of blood from the kidney may operate in acute heart failure is not denied by these studies. Neurogenic stimuli do affect the renal vascular bed. Smith (5) has shown that orthostasis and emotional stimuli induce renal ischemia. An in- crease in renal vasoconstriction with further depression of renal plasma flow is also obtained in essential hypertension (9) and in congestive failure (10) under these conditions. In some patients with hypertension it appears that neurogenic factors are the modus operandi of the renal ischemia. Page, Corcoran and co-workers (11) have observed renal hyperemia under spinal anesthesia in a group of "neurogenic" hypertensives. However, in some of their patients and in the reports of other workers $(6,12)$, no such decrease in renal arteriolar resistance occurs. The use of tetra- 


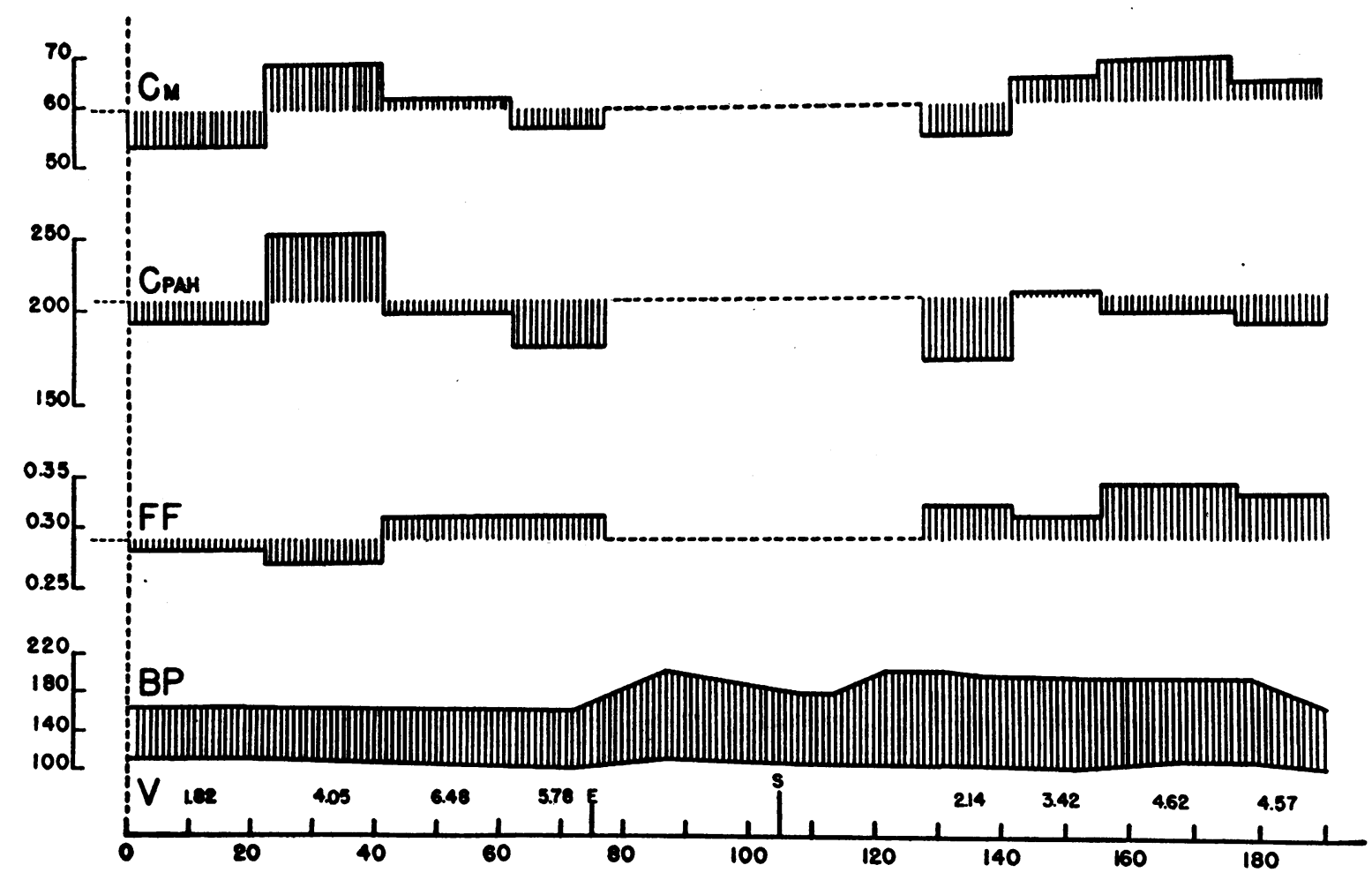

Fig. 2. The Typical Response of the Renal Circulation in Congestive Heart failure to High Spinal Anesthesia. Patient I. F. Symbols as in Fig. 1

There is no significant change in the renal plasma flow or glomerular filtration rate during anesthesia to the second thoracic segment as compared to control periods before anesthesia.

ethylammonium ion as an autonomic ganglionic blocking agent by Lyons and co-workers (13) was reported to have produced renal vasodilatation; the latter, however, consisted merely of a maintained renal blood flow in the presence of a fall in blood pressure. No renal hyperemia was observed. It would be of interest to follow the renal circulatory changes with this drug if the concomitant drop in blood pressure could be avoided.

Our inability to alter renal blood flow in chronic heart failure by removal of nerve impulses makes it highly improbable that the renal changes associated with congestive failure are produced by this selfsame mechanism. It would therefore appear far more likely that the renal circulatory changes observed, are mediated through some humoral mechanism. This mechanism must involve the formation of a substance or substances either local in the kidney or extrarenal and would account for the observed phenomena in heart failure ; namely, the increased peripheral resistance with maintenance of a normal blood pressure in the presence of a decreased cardiac output and the high filtration fraction in the presence of a decreased renal blood flow. Merrill (2) has demonstrated increased amounts of renin in the renal venous blood in eight of 11 patients with congestive heart failure. Shorr, $Z$ weifach and associates (14) have reported the release of vaso-excitor material (VEM) from ischemic kidneys in vivo and its production anaerobically by kidney cortex in vitro. May it not be liberated from the kidneys in chronic heart failure as a result of the renal hypoxia? This is now being investigated.

\section{SUM MARY}

1. Renal plasma flow and glomerular filtration rates were determined in 11 patients with chronic congestive heart failure before and after high spinal anesthesia. The mean change in these renal functions was insignificant. 
2. It is concluded that a neurogenic mechanism is not required for the maintenance of the increased tone of the renal arterioles in chronic congestive heart failure.

3. The nature of the humoral mechanism involved is unknown, but among the possibilities are renin and (VEM), both released in response to renal ischemia.

\section{ACKNOWLEDGMENTS}

We are indebted to Dr. Benjamin Cohen, anesthetist, Montefiore Hospital, for performing the spinal anesthesia and to Dr. Jacob Grossman for assistance in conducting some of the studies.

\section{BIBLIOGRAPHY}

1. Mokotoff, R., Ross, G., and Leiter, L., Renal plasma flow and sodium reabsorption and excretion in congestive heart failure. J. Clin. Invest., 1948, 27, 1.

2. Merrill, A. J., Morrison, J. L., and Brannon, E. S., Concentration of renin in renal venous blood in patients with chronic heart failure. Am. J. Med., 1946, 1, 468.

3. Merrill, A. J., Edema and decreased renal blood flow in patients with chronic congestive heart failure: evidence of "forward failure" as the primary cause of edema. J. Clin. Invest., 1946, 25, 389.

4. Smith, H. W., Rovenstine, E. A., Goldring, W., Chasis, H., and Ranges, H. A., The effects of spinal anesthesia on the circulation in normal, unoperated man with reference to the autonomy of the arterioles, and especially those of the renal circulation. J. Clin. Invest., 1939, 18, 319.
5. Smith, H. W., Lectures on the Kidney. University Extension Division, University of Kansas, Lawrence, Kansas, 1943, 52.

6. Goldring, W., and Chasis, H., Hypertension and Hypertensive Disease. Commonwealth Fund, New York, 1944.

7. Smith, H. W., Personal communication.

8. Harrison, T. R., Failure of the Circulation. The Williams and Wilkins Company, Baltimore, 1936.

9. Pfeiffer, J. B., and Ripley, H. S., Measurement of renal blood flow and glomerular filtration during variation in blood pressure related to changes in emotional state and life situations. J. Clin. Invest., 1947, 26, 1193.

10. Unpublished data.

11. Page, I. H., Taylor, R. D., Corcoran, A. C., and Mueller, L., Correlation of clinical types with renal function in arterial hypertension. II. Effect of spinal anesthesia. J. A. M. A., 1944, 124, 736.

12. Talbott, J. H., Castleman, B., Smithwick, R. H., Melville, R. S., and Pecora, L. J., Renal biopsy studies correlated with renal clearance observations in hypertensive patients treated by radical sympathectomy. J. Clin. Invest., 1943, 22, 387.

13. Lyons, R. H., Moe, G. K., Neligh, R. B., Hoobler, S. W., Campbell, K. N., Berry, R. L., and Rennick, B., The effects of blockade of the autonomic ganglia in man with tetraethylammonium. Preliminary observations on its clinical application. Am. J. M. Sc., 1947, 213, 315.

14. Zweifach, B. W., Baez, S., and Shorr, E., Hepatorenal factors in circulatory homeostasis; effects of acute renal ischemia on the renal vaso-excitor mechanisms. Federation Proc., 1947, 6, 232. 